\title{
Evidence-based treatments for cluster headache
}

This article was published in the following Dove Press journal:

Therapeutics and Clinical Risk Management

9 November 2015

Number of times this article has been viewed

\section{Rubesh Gooriah \\ Alina Buture \\ Fayyaz Ahmed}

Department of Neurology, Hull Royal Infirmary, Kingston upon Hull, UK
Correspondence: Rubesh Gooriah Department of Neurology, Hull Royal Infirmary, Anlaby Road, Hull HU3 2JZ, UK Email rubesh@doctors.org.uk
Abstract: Cluster headache $(\mathrm{CH})$, one of the most painful syndromes known to man, is managed with acute and preventive medications. The brief duration and severity of the attacks command the use of rapid-acting pain relievers. Inhalation of oxygen and subcutaneous sumatriptan are the two most effective acute therapeutic options for sufferers of $\mathrm{CH}$. Several preventive medications are available, the most effective of which is verapamil. However, most of these agents are not backed by strong clinical evidence. In some patients, these options can be ineffective, especially in those who develop chronic $\mathrm{CH}$. Surgical procedures for the chronic refractory form of the disorder should then be contemplated, the most promising of which is hypothalamic deep brain stimulation. We hereby review the pathogenesis of $\mathrm{CH}$ and the evidence behind the treatment options for this debilitating condition.

Keywords: cluster headache, pathogenesis, vasoactive intestinal peptide, suprachiasmatic nucleus

\section{Introduction}

Cluster headache $(\mathrm{CH})$, the commonest of the trigeminal autonomic cephalalgias (TAC) and the most painful of the primary headache disorders, is characterized by attacks of severe, strictly unilateral pain, which is orbital, supraorbital, temporal, or in any combination of these sites, lasting 15-180 minutes and occurring from once every other day to eight times a day. ${ }^{1}$ The pain of $\mathrm{CH}$ is associated with ipsilateral conjunctival injection, lacrimation, nasal congestion, rhinorrhea, forehead and facial sweating, miosis, ptosis and/or eyelid edema, and/or restlessness or agitation. ${ }^{1}$ It was reported as early as 1745 in a textbook written by van Swieten, and the description of the attack would have met the current International Headache Society criteria. ${ }^{2} \mathrm{CH}$ affects $\sim 0.3 \%$ of the population, although there is still a debate on the exact prevalence due to a marked variation in the estimated prevalence in various studies (between 56 and 381 per 100,000 population). ${ }^{3-5}$ Men are affected around three times more often than women. The term episodic $\mathrm{CH}$ refers to $\mathrm{CH}$ attacks occurring in periods lasting from 7 days to 1 year, separated by pain-free periods lasting for at least 1 month. ${ }^{1}$ This affects $\sim 85 \%$ of sufferers of $\mathrm{CH}$. ${ }^{6}$ The chronic form of the disease, which occurs for $>1$ year without remission or with remissions lasting $<1$ month, ${ }^{2}$ can evolve from the episodic form or can develop de novo as primary chronic cluster headache $(\mathrm{CCH})$. The rarest form is the secondary episodic pattern that starts as the chronic form and then becomes episodic. ${ }^{7}$ Some individuals with $\mathrm{CCH}$ fail to respond to standard treatments and are considered to have refractory $\mathrm{CCH}$. A consensus statement from the European Headache Federation defines refractory $\mathrm{CCH}$ as $\mathrm{CCH}$ with at least three severe attacks per week, despite at least three consecutive trials of adequate preventive treatments have been tested. ${ }^{8}$

\section{Pathogenesis}

Although $\mathrm{CH}$ is clinically well defined, the exact cause and pathophysiology of this disorder remain nebulous. The three fundamental aspects of the condition are the 
distribution of pain in the first division of the trigeminal nerve, the autonomic features, and the cyclical pattern of the attacks. Any pathophysiological model, to be valid, should incorporate these three features. The trigeminal innervation of the cranial circulation contains a number of neuropeptides, including calcitonin gene-related peptide (CGRP), substance $P$, and vasoactive intestinal peptide. Stimulation of the trigeminal ganglion leads to the release of CGRP and substance P into the cranial circulation. ${ }^{9}$ Elevated plasma levels of CGRP in the external jugular vein have been found during $\mathrm{CH}$ attacks. ${ }^{10}$ Plasma levels of CGRP are also elevated interictally in patients with episodic $\mathrm{CH}$ during the bout compared to those in remission. ${ }^{11}$ This finding may indicate a hyperactive state of the trigeminal system during the bout. From the autonomic symptoms of CHs, it can be deduced that ipsilateral sympathetic dysfunction (ptosis, miosis, and facial sweating) and parasympathetic activation occur (rhinorrhea, lacrimation, and nasal congestion). The latter is mediated through the seventh cranial nerve. ${ }^{10}$ The early "vascular theory" was supported by angiography demonstrating changes in the internal carotid artery in a patient suffering from an acute $\mathrm{CH} .{ }^{12}$ Since the parasympathetic and sympathetic fibers of the trigeminal nerve converge in the region of the cavernous sinus, this has been thought to be a likely site of involvement. ${ }^{13,14}$

However, the episodic and circadian pattern cannot be explained by a vascular phenomenon alone, as they suggest dysfunction of a central pacemaker, namely, the hypothalamus. ${ }^{15}$ Testosterone levels have been found to be lower in patients with $\mathrm{CH}$ during the attack, ${ }^{16-18}$ providing initial evidence for the involvement of the hypothalamus. This was supported by evidence of reduced stimulation by thyrotropin-releasing hormone and observations of disordered circadian rhythm for cortisol, luteinizing hormone, growth hormone, and prolactin. ${ }^{19}$ Melatonin is suspected to be involved in $\mathrm{CH}$ genesis, mainly because it is a sensitive marker of endogenous rhythms, which are disrupted in $\mathrm{CH}$. Smokers have lower levels of melatonin than nonsmoking patients with $\mathrm{CH} .{ }^{20}$ Melatonin production is regulated by a multisynaptic pathway from the biological clock in the suprachiasmatic nucleus of the hypothalamic gray matter to the pineal gland. ${ }^{21}$ Circuits between the retina and the hypothalamus are thought to provide light cues for the circadian rhythm. ${ }^{22}$ A suppressed nocturnal peak in melatonin is seen during the active phase of a $\mathrm{CH},{ }^{23,24}$ providing further evidence for a role of the hypothalamus gray matter in the pathophysiology of CHs. May et al, in a landmark study, confirmed a highly specific activation of the hypothalamic gray matter using positron emission tomography images in nitroglycerine-induced and spontaneous $\mathrm{CHs}$, providing indisputable evidence for its role in $\mathrm{CH}^{25}$ The term "neurovascular headache", with reference to migraine, $\mathrm{CH}$, and related disorders, is therefore a more appropriate term. ${ }^{26}$

\section{Acute treatment}

Given the excruciating pain caused by $\mathrm{CH}$, acute treatment focuses on the prompt relief of pain. Because the pain evolves very rapidly, oral therapy is not as effective as it is for the treatment of migraine. Oxygen and parenteral triptans provide the fastest, most effective, and reliable alleviation of pain.

\section{Oxygen therapy}

Oxygen is an acute treatment for $\mathrm{CH}$ and is the first line of treatment together with injectable triptans. It was first used effectively by Horton. ${ }^{27}$ The mechanism of action of oxygen in $\mathrm{CH}$ is not fully understood. ${ }^{28}$ It has been shown that oxygen has a direct inhibitory effect on the cranial parasympathetic fibers. ${ }^{29}$ Oxygen treatment had no effect on the activation of trigeminal afferents in response to the stimulation of dural structures. ${ }^{29}$ It appears that oxygen acts as a neuromodulator affecting neurotransmitter levels and works through deactivation of the trigemino-autonomic reflex arc. ${ }^{28}$ Inhalation of pure oxygen via a nonrebreathing facial mask, with a flow rate of at least $7 \mathrm{~L} / \mathrm{min}$, effectively stops $\mathrm{CH}$ attacks. ${ }^{30,31}$ Rozen published a case series of three patients who were refractory to oxygen inhalation at low-flow rates $(7-10 \mathrm{~L} / \mathrm{min}) .{ }^{32} \mathrm{High}-$ flow oxygen (14-15 L/min) was tried that resulted in complete headache relief in two out of the three patients, with the third patient experiencing 70\%-100\% relief. Cohen et al compared high-flow $100 \%$ oxygen $(12 \mathrm{~L} / \mathrm{min})$ to air in a double-blind, randomized, placebo-controlled, crossover trial. ${ }^{33}$ In $78 \%$ of the attacks, patients with $\mathrm{CH}$ experienced freedom from pain or adequate relief at 15 minutes when they were treated with high-flow oxygen, while only $20 \%$ had the same response to placebo. Hyperbaric oxygen treatment as an acute treatment seems to have little effect. In a double-blind, placebocontrolled crossover study involving 16 patients with $\mathrm{CH}$, two hyperbaric oxygen sessions were not more effective than two sham treatments in interrupting the $\mathrm{CH}$ period. ${ }^{34}$ The effect was thought to be caused by the hyperbaric condition itself, or by a marked placebo effect. A Cochrane review concluded that there is insufficient evidence to establish the effects of hyperbaric oxygen treatment as a treatment for an acute $\mathrm{CH}$ attack or as prophylaxis. ${ }^{35}$

\section{Triptans}

The results of a randomized, double-blind, placebo-controlled crossover study that was conducted to assess the efficacy and 
tolerability of subcutaneous sumatriptan in 49 patients with $\mathrm{CH}$ were published in $1991 .{ }^{34}$ Patients were randomized to either $6 \mathrm{mg}$ of subcutaneous sumatriptan for one attack or placebo for another attack. Results of the two attacks could be fully evaluated for 39 patients and the severity of headaches decreased in $74 \%$ of the attacks within 15 minutes of treatment with sumatriptan as compared with $26 \%$ of the attacks, where placebo was administered $(P<0.001)$. Significantly more patients were pain free at 10 minutes and 15 minutes following the administration of sumatriptan, compared with placebo. ${ }^{36}$ This was followed by a further, larger dosecomparison study with similar crossover design to assess the efficacy, safety, and tolerability of subcutaneous sumatriptan (6 $\mathrm{mg}$ and $12 \mathrm{mg}$ ) in comparison with placebo in 134 inpatients with $\mathrm{CH} .{ }^{37}$ The $12 \mathrm{mg}$ dose was not significantly better than the $6 \mathrm{mg}$ dose but was associated with more adverse events. The $6 \mathrm{mg}$ dose was therefore recommended for the acute treatment of $\mathrm{CH}$. In an open-label study, the long-term safety and efficacy of subcutaneous sumatriptan was studied in 138 patients with $\mathrm{CH} .{ }^{38} \mathrm{~A}$ total of 6,353 attacks, which occurred over 3 months, were examined. Headache relief was obtained in $96 \%$ of attacks. Sumatriptan was well tolerated, and more frequent use of the drug did not result in an increase in adverse events. There was also no evidence for decreased efficacy of the drug with prolonged use, ${ }^{38}$ and this was supported by a further long-term study. ${ }^{39}$ Subcutaneous sumatriptan is $\sim 8 \%$ less effective in patients with chronic $\mathrm{CH}$ than in patients with episodic $\mathrm{CH}^{39}{ }^{39}$ It is also not effective when taken preemptively in an attempt to prevent an oncoming attack. ${ }^{40}$

Intranasal sumatriptan is also effective for the acute treatment of $\mathrm{CH}$. In a double-blind, placebo-controlled randomized trial, 118 patients with episodic or chronic $\mathrm{CH}$ had one attack treated with $20 \mathrm{mg}$ sumatriptan nasal spray and another one, at least 24 hours later, with matching placebo. Headache severity was assessed at 5 minutes, 10 minutes, 15 minutes, 20 minutes, and 30 minutes. The primary outcome measure was headache response (a decrease in pain from very severe, severe, or moderate to mild or none) at 30 minutes. In this study, 154 attacks were treated: 77 with sumatriptan and 77 with placebo. The responder rates at 30 minutes were $57 \%$ for intranasal sumatriptan and $26 \%$ for placebo $(P=0.002)$. Pain-free rates at 30 minutes were $47 \%$ for intranasal sumatriptan and $18 \%$ for placebo $(P=0.003) .{ }^{41}$ This confirmed the results of an earlier pilot study where 154 attacks were treated. ${ }^{42}$ However, intranasal sumatriptan is not as effective as subcutaneous sumatriptan. The latter was found to completely relieve pain within 15 minutes in significantly more attacks than intranasal sumatriptan (94.2\% vs $13.5 \%) .{ }^{43}$ Oral zolmitriptan is effective in the acute treatment of $\mathrm{CH}$. A multicenter, double-blind, randomized, placebo-controlled crossover study involving 124 patients with $\mathrm{CH}$ reported statistically significant difference $(47 \%$ vs 29\%; $P=0.02$ ) between zolmitriptan $10 \mathrm{mg}$ and placebo at 30 minutes. ${ }^{44}$ Mild or no pain at 30 minutes was reported by $60 \%, 57 \%$, and $42 \%$ patients treated with zolmitriptan $10 \mathrm{mg}$, zolmitriptan $5 \mathrm{mg}$, and placebo (both $P \leq 0.01$ vs placebo), respectively. Zolmitriptan $10 \mathrm{mg}$ was significantly superior to placebo in patients with episodic $\mathrm{CH}$ for secondary endpoints, whereas zolmitriptan $5 \mathrm{mg}$ was significantly superior to placebo for three of the four secondary endpoints. ${ }^{44}$ Although the efficacy of oral zolmitriptan does not compare to that of subcutaneous sumatriptan, it is a useful option in patients who are needle phobic and in cases where oxygen treatment is not desirable. Intranasal zolmitriptan has also been found to be effective. . $^{45,46}$

\section{Ergotamine}

Oral ergotamine was first introduced in $1945^{47}$ and has been in use for the treatment of $\mathrm{CH}$ for many years. Dihydroergotamine (DHE) is marketed in the United States in injectable and intranasal formulations. When administered intravenously, DHE-45 provides rapid relief from $\mathrm{CH}$ within 15 minutes, whereas intramuscular and subcutaneous routes are not as effective because of the lower bioavailability and substantial time to peak concentration. ${ }^{7}$ For this reason, it is not a practical alternative to sumatriptan. The need for an intravenous access limits its use to inpatient settings. Intranasal DHE has some efficacy, but studies supporting its use are scarce. In a double-blind, placebo-controlled trial involving 25 patients, 137 attacks were treated with DHE spray and 133 attacks were treated with placebo. ${ }^{47} \mathrm{DHE}$ had a significant effect on the intensity of the attack but failed to affect its duration and frequency. ${ }^{47}$ The most serious side effect of ergotamine is arterial spasm due to its potent vasoconstrictor effect. It is contraindicated in, among others, coronary or peripheral vascular disease, arterial hypertension, and diseases of the liver and kidney. ${ }^{48}$

\section{Lidocaine}

Following the successful treatment of $\mathrm{CH}$ with cocainization of the pterygopalatine fossa, $4 \%$ intranasal lidocaine has been tried in five patients, four of whom obtained rapid relief from nitrate-induced $\mathrm{CH}^{49}$ Robbins found that intranasal lidocaine provided moderate relief in $27 \%$ of the 30 treated males. ${ }^{50}$ A small double-blind, placebo-controlled 
trial, involving 15 patients treated with intranasal cocaine or lidocaine or placebo, showed that all patients treated with either cocaine or lidocaine achieved complete relief, although this occurred after 30 minutes on average. ${ }^{51}$ Lidocaine is therefore useful as an adjunctive therapy, but not as a firstline therapy. When applying lidocaine, the head should be reclined by $45^{\circ}$ and rotated to the affected side by $30^{\circ}-40^{\circ}$. Side effects are mild. ${ }^{50}$

\section{Short-term preventive treatment Corticosteroids}

The efficacy of corticosteroids as a short-term transitional therapy has been shown in open-label studies and case studies, ${ }^{52-55}$ but there are no methodologically robust or largescale controlled trials. Its benefits were, again, first noted by Horton. ${ }^{56}$ It is not fully understood how corticosteroids work in $\mathrm{CH}$. Administration of corticosteroids has been found to significantly decrease CGRP plasma levels and increase nocturnal urinary excretion of 6-sulfatoxymelatonin - the stable metabolite of melatonin. ${ }^{57}$ Antonaci et al treated 13 patients with $\mathrm{CH}$ with intravenous methylprednisolone at a dose of $30 \mathrm{mg} / \mathrm{kg} .{ }^{58}$ In all cases, the attacks stopped after administration of methylprednisolone and did not recur for $\geq 2$ days. There was a significant difference between the mean frequency of daily attacks during the 7 days preceding methylprednisolone administration and the 7-day period following the treatment. The largest open-label study involving 77 patients reported significant relief from $\mathrm{CH}$ in $77 \%$ of the patients and partial relief in a further $12 \% .{ }^{59}$ A prospective, randomized, double-blind, placebo-controlled trial, to assess whether oral prednisone added to first-line agent verapamil helps reduce the number and intensity of $\mathrm{CH}$ attacks in the beginning of a $\mathrm{CH}$ episode as compared to monotherapy with verapamil, is currently ongoing in eight German centers (German Clinical Trials Register DRKS00004716).$^{60}$ Despite the lack of class I evidence, the clinical experiences and conclusion of investigators suggest a clear benefit for corticosteroids in $\mathrm{CH}$. Concomitant administration of another prophylactic agent for $\mathrm{CH}$ is recommended because attacks often recur when the corticosteroid dose is tapered.

\section{Methysergide}

Methysergide, the active metabolite of which is methylergometrine, ${ }^{61}$ is a potent drug first used by Sicuteri. ${ }^{62}$ There are no placebo-controlled trials to assess the efficacy of methysergide in $\mathrm{CH}$. In open studies, the proportion of patients who benefited from methysergide ranged from $20 \%$ to $73 \%$, and the drug was found to be more effective in episodic $\mathrm{CH}^{63}$ It is often administered at a daily dose of 4-8 $\mathrm{mg}$ and can be increased up to $12 \mathrm{mg} .{ }^{64}$ Given the risk of retroperitoneal, pulmonary, cardiac, and pleural fibrosis with long-term use, it is only recommended for no more than 6 months at a time with an interruption of 1 month to 2 months in between. It is therefore most suitable for patients who have short bouts of $\mathrm{CH}$ lasting $<4$ months. Other side effects include nausea, dizziness, epigastric pain, and leg cramps. ${ }^{48}$ Nevertheless, the manufacturer of methysergide has ceased the production of this drug.

\section{Long-term preventive treatment Verapamil}

The exact mode of action of verapamil in $\mathrm{CH}$ is unknown but is thought to be due to an effect on either the low- (T-type) or the high-voltage-activated $\mathrm{Ca}^{2+}$ channels (L-, N-, P-, Q-type) in the hypothalamus. ${ }^{65}$ Evidence for its efficacy in $\mathrm{CH}$ arises from a handful of open studies and randomized placebocontrolled trials, ${ }^{66,67}$ giving it a class $\mathrm{C}$ level of evidence. ${ }^{68}$ Nevertheless, it is considered the mainstay of prophylactic treatment for $\mathrm{CH}$ as per the European guidelines. ${ }^{69}$ Leone et al conducted a randomized double-blind, placebo-controlled study involving 30 patients (15 receiving verapamil $120 \mathrm{mg}$ qid and 15 receiving placebo) ${ }^{67} \mathrm{~A}$ significant reduction in the attack frequency was found in the verapamil group. Bussone et al found verapamil to be as effective as lithium for the prevention of chronic $\mathrm{CH}$, but verapamil had a more rapid onset of action. ${ }^{70}$ A dose ranging from $240 \mathrm{mg} / \mathrm{d}$ to $960 \mathrm{mg} / \mathrm{d}$ is employed as the treatment of choice for both episodic and chronic $\mathrm{CH} .{ }^{71}$ Patients are usually started on $80 \mathrm{mg}$ three times daily following a baseline electrocardiogram (ECG), and thereafter, the total daily dose is increased in increments of $80 \mathrm{mg}$ every 10-14 days. An ECG is performed prior to each increment. ${ }^{71}$ Some patients with $\mathrm{CH}$ may even need unusual, very high daily dose from $720 \mathrm{mg}$ to $1,200 \mathrm{mg},{ }^{68}$ which is at least twice the dose used in cardiovascular disorders. ${ }^{65}$ Regular monitoring with ECG is required with the use of verapamil and is even more important with the use of higher doses. Lanteri-Minet et al identified 29 patients who were treated with very high doses of verapamil ( $\geq 720 \mathrm{mg} / \mathrm{d}$ ) for $\mathrm{CH}$, which represented $14.8 \%$ of patients with $\mathrm{CH}$ treated in two centers representative of French headache tertiary centers. ${ }^{72}$ ECG changes were found in eleven (38\%) patients: bradycardia (heart rate $60 \mathrm{bpm}$ ) in seven patients, first-degree heart block (PR interval $>0.2 \mathrm{~s}$ ) in two patients, second-degree heart block in one patient, and third-degree heart block in one patient. This resulted in verapamil discontinuation in two patients 
with a third one requiring a dose reduction. These adverse events presented late in eight of the eleven patients and at least 2 years after initiating high-dose verapamil, suggesting the need for regular ECG monitoring in these patients. We perform biannual ECGs for those on long-term treatment. Verapamil is otherwise well tolerated. Other side effects include edema, gastrointestinal discomfort, constipation, and dull headache. ${ }^{73}$

\section{Lithium}

A nonsystematic review of case reports and case series conducted in the 1970s suggested that lithium may be an effective preventive treatment for $\mathrm{CH}$, but the response was more robust in chronic than in episodic $\mathrm{CH} .{ }^{74}$ Collectively, in $>28$ clinical trials involving 468 people, good to excellent results were reported in $78 \%$ of sufferers of chronic $\mathrm{CH}$ and in $63 \%$ of subjects with episodic $\mathrm{CH} .{ }^{74}$ A placebo-controlled trial, however, failed to replicate these results, although the duration of treatment with lithium was short. ${ }^{75}$ The initial starting daily dosage is either $300 \mathrm{mg}$ tid or $450 \mathrm{mg}$ sustained release. ${ }^{15}$ However, trials comparing the two formulations are not available, but a long half-life affords the option of a once daily dosage regimen and allows for potentially better compliance. The concentration of the drug in the plasma should be monitored and kept between $0.6 \mathrm{mmol} / \mathrm{L}$ and $1.2 \mathrm{mmol} / \mathrm{L} .{ }^{76}$ Liver, renal, and thyroid functions as well as electrolytes should be monitored regularly. There is current consensus, based on the observational evidence, that lithium, although commonly used and believed to be effective, is less effective than verapamil and causes more adverse effects. It is therefore recommended for chronic $\mathrm{CH}$ when other drugs are ineffective or contraindicated.

\section{Topiramate}

Topiramate has numerous mechanisms of action, including inhibition of glutamatergic excitatory amino acid transmission, inhibition of voltage-gated calcium channels, enhancement of gamma-aminobutyric acid (GABA)-evoked currents, fast $\mathrm{Na}^{+}$channel blockade, and carbonic anhydrase inhibition. ${ }^{77}$ It also has an inhibitory effect on trigeminovascular nociceptive neurons activated by stimulation of the superior sagittal sinus in rats. ${ }^{78}$ Topiramate has been shown to be effective in reducing the frequency of $\mathrm{CH}$ attacks in open studies. ${ }^{79-81}$ It was associated with prompt improvement in ten sufferers of $\mathrm{CH}$, nine of whom achieved remission within 3 weeks. ${ }^{80} \mathrm{In}$ a prospective study involving 26 patients (12 with episodic $\mathrm{CH}$ and 14 with chronic $\mathrm{CH}$ ), topiramate rapidly induced $\mathrm{CH}$ remission in 15 patients, reduced the number of attacks by $>50 \%$ in six patients, and reduced the $\mathrm{CH}$ period duration in 12 patients. The average time to remission was 14 days. ${ }^{81}$ Usual dosing is $100 \mathrm{mg} / \mathrm{d}$ (range: $25-200 \mathrm{mg}$ ). It appears that topiramate has a therapeutic window in $\mathrm{CH}$, with some patients reporting worsening of attacks when the dosage is increased beyond a certain limit, only to improve when the dose is again reduced. ${ }^{82}$ Side effects include numbness and tingling in the extremities, weight loss, and cognitive difficulties. It is contraindicated in those with renal calculi.

\section{Valproic acid}

Valproic acid is thought to block neurogenic inflammation within the meninges through $\mathrm{GABA}_{\mathrm{A}}$-mediated receptors. ${ }^{83}$ Hering and Kuritzky investigated the effect of prophylactic treatment with sodium valproate $(600-2,000 \mathrm{mg} / \mathrm{d})$ in 15 patients with $\mathrm{CH}$ (13 with episodic $\mathrm{CH}$ and two with chronic $\mathrm{CH}) .{ }^{84}$ It was found to be effective in eleven patients, nine of whom had complete control of their symptoms. The time to remission was between 1 day and 4 days. Further open trials support the use of valproic acid, ${ }^{85,86}$ but there is no adequate double-blind, place-controlled trial supporting this. El Amrani et al failed to show any difference between sodium valproate and placebo in a double-blind trial involving 96 patients. ${ }^{87}$ The high placebo rate observed was likely due to spontaneous remission of $\mathrm{CH}$ rather than a true placebo effect. In fact, subjects in the placebo group had a shorter previous mean duration of their $\mathrm{CH}$ compared to the sodium valproate group (62.4 days vs 78.3 days). In those who have concomitant migrainous symptoms, it has been suggested that divalproex sodium is more likely to be beneficial. ${ }^{88}$ Common side effects include tremors, alopecia, and weight gain, while pancreatitis, thrombocytopenia, and liver dysfunction have also been described with valproic acid.

\section{Other drugs}

Between $10 \%$ and $20 \%$ of patients with $\mathrm{CH}$ develop resistance to conventional treatment for $\mathrm{CH}$. In some, intolerance and contraindications may further restrict their use. Pizotifen, ${ }^{89,90}$ levetiracetam, ${ }^{91,92}$ gabapentin, ${ }^{93,94}$ baclofen, ${ }^{95}$ intranasal capsaicin,,${ }^{96}$ and melatonin ${ }^{97,98}$ have been shown to be effective in small studies and can therefore be considered as a third-line option in refractory patients.

\section{Interventional approaches}

\section{Resective and ablative surgery}

In drug-resistant patients, surgical procedures have to be taken into consideration. It is important that the patient has exhausted all the available medical options. Sufferers of 
episodic $\mathrm{CH}$ rarely require surgical treatments as remission occurs. Those with chronically intractable and strictly unilateral $\mathrm{CH}$ are the best candidates for destructive surgery. Several surgical procedures have been tried in patients with chronic $\mathrm{CH}$, most of which are now obsolete with scattered case reports available in the literature. Destructive methods such as trigeminal section, ${ }^{99}$ glycerol rhizotomy, ${ }^{100,101}$ and radiosurgery ${ }^{102,103}$ of the trigeminal nerve have shown mixed results with some patients being left with anesthesia dolorosa - a painful numbness described by some $\mathrm{CH}$ patients as a much worse sensation than the $\mathrm{CH}$ itself because of its continuous nature. ${ }^{82}$ Complete resection of the trigeminal nerve has been found to be ineffective in preventing headache attacks and autonomic symptoms. ${ }^{104}$ Microvascular decompression of the trigeminal nerve has been reported to be effective in a case series of 28 patients with chronic $\mathrm{CH}$ achieving $>90 \%$ pain relief in 15 patients and $>50 \%$ pain relief in $73.3 \% .{ }^{105}$ However, follow-up of an average of 5.3 years showed a decrease to $46.6 \%$, and repeat procedures were found to be unhelpful.

\section{Neurostimulation}

\section{Hypothalamic deep brain stimulation}

Hypothalamic deep brain stimulation is perhaps the most promising surgical intervention. The hypothalamus represents an attractive target since, as discussed earlier, it is central to the pathophysiology of $\mathrm{CH}$. The first patient to receive hypothalamic deep brain stimulation was suffering from severe bilateral chronic $\mathrm{CH}$ and had failed previous destructive surgeries to the right trigeminal nerve, and following bilateral electrode implantation, the patient remained crisis free without the need for prophylactic medications. ${ }^{106}$ Long-term follow-up (mean of 23 months) in 16 patients with chronic drug-refractory $\mathrm{CH}$ revealed that 13 patients were pain free or almost pain free and the remaining three had improved. ${ }^{107}$ No persistent side effects were noted. Hypothalamic deep brain stimulation (DBS) was deemed effective, safe, and well tolerated. Other studies have confirmed these positive results in the majority of the treated patients. ${ }^{108,109}$ However, it is not without risks, with one patient succumbing to intracerebral hemorrhage postoperatively. ${ }^{108}$ The risk of hemorrhage following DBS for $\mathrm{CH}$ is 3\%, which is similar to that seen with movement disorders. ${ }^{110}$ Criteria for the patient selection for this procedure have been proposed. ${ }^{111}$

\section{Occipital nerve stimulation}

Occipital nerve stimulation (ONS) is an invasive but nondestructive surgical option for intractable cases of $\mathrm{CH}$. Burns et al retrospectively assessed the outcome of ONS in 14 patients with chronic $\mathrm{CH}$ who were implanted with bilateral electrodes. ${ }^{112}$ At a median follow-up of 17.5 months, ten of the patients had improved. Six patients reported a moderate to marked improvement. Clinical benefit was seen from days to weeks, and responders reported that their attacks reappeared within hours or days after switching off the device. ONS aborted attacks in one patient. In a prospective pilot trial with a mean follow-up of 36.8 months, among the 14 patients who successfully had the device implanted, eleven reported an improvement of at least $90 \%$, with $60 \%$ of patients becoming pain free for prolonged periods. Two patients did not respond. Significant electrode migration was seen in one patient. Battery depletion was, however, seen in nine of the 14 patients. One patient had an immediate postoperative infection of the device, with two more having delay infections. Other small studies have also reported benefits of ONS. ${ }^{113,114}$

\section{Nerve blocks and injections Greater occipital nerve blockade}

Greater occipital nerve (GON) blockade is effective in $\mathrm{CH}$ treatment. It has been tried on the basis that the GON, a C2 nerve branch, could interrupt the trigeminal autonomic reflex pathway given the functional connectivity between trigeminal and cervical nerves. Lambru et al studied 83 patients with chronic $\mathrm{CH}$ and after the first GON block, 47 (57\%) patients responded with a median response duration of 21 days. ${ }^{115}$ Leroux et al randomized 43 patients with chronic and episodic $\mathrm{CH}$ to either three suboccipital steroid injections or placebo as add-on to their oral prophylactic treatment. ${ }^{116}$ In the verum group, 20 of 21 patients had a mean of two or fewer daily attacks after injections compared with 12 of 22 controls (odds ratio: 14.5, 95\% confidence interval: 1.8-116.9, $P=0.012$ ). Patients who received steroid injections also had fewer attacks in the first 15 days of study than did controls $(P=0.004)$. No serious adverse events were noted. The most common adverse events were injection-site neck pain and non-CH. In another double-blind, placebo-controlled trial, 16 patients with episodic $\mathrm{CH}$ and seven with chronic $\mathrm{CH}$ were randomized to betamethasone or saline. ${ }^{117}$ Eleven patients in the verum group (85\%), of which three had chronic $\mathrm{CH}$, became attack free in the 1 st week after the injection compared to none in the placebo group $(P=0.0001)$. Among them, eight remained free from attacks for 4 weeks $(P=0.0026)$. Remission lasted between 4 months and 26 months in five patients. It was found that a single suboccipital steroid injection completely suppresses attacks in $>80 \%$ of patients with $\mathrm{CH} .{ }^{115}$ Although small, these trials suggest that GON blockade is effective for short-term transitional prophylaxis. 
Supraorbital, auriculotemporal, and supratrochlear blocks have been tried, although no controlled evidence exists for their use and they are not routinely performed.

\section{Botulinum toxin}

Botulinum toxin is effective in chronic migraine and perhaps in other painful conditions such as painful bladder syndrome and anal fissures. ${ }^{118,119}$ It has been shown to reduce plasma levels of CGRP in patients with chronic migraine. ${ }^{120}$ Given the role of CGRP in $\mathrm{CH}$, botulinum toxin appears to be an attractive proposition for sufferers of $\mathrm{CH}$, and this has been assessed in an open-label study. ${ }^{121}$ Twelve patients with $\mathrm{CH}$ were enrolled, nine of whom had chronic $\mathrm{CH}$. An improvement in the primary study endpoint - reduction of attack frequency - was seen in $25 \%(3 / 12)$ of all study patients and in 33\% (3/9) of patients with chronic $\mathrm{CH}$ after administration of $50 \mathrm{IU}$ of botulinum toxin A. Botulinum toxin has also been reported to be effective in small case studies and case reports. ${ }^{122,123}$ However, there is still insufficient evidence to warrant the use of botulinum toxin in $\mathrm{CH}$, and adequate randomized double-blind, placebocontrolled trials are needed to support its use.

\section{Conclusion}

$\mathrm{CH}$, a severely disabling condition, is often adequately managed with currently available pharmacotherapy, despite the scarcity of robust evidence for the majority of the drugs used. A subset of patients also develop a chronic refractory form of the condition, whereby conventional management is ineffective. Invasive procedures are then considered, but, again, strong evidence supporting their efficacy is lacking and they are certainly not without risks. They should therefore be reserved for patients who are intractable to all available drugs. Given the abundant evidence implicating the hypothalamus as a key role player in generating $\mathrm{CH}$, developing and perfecting therapeutic options targeting this area is essential. Deep brain stimulation of the hypothalamus is at present the most attractive option for this subgroup of patients. However, larger studies are needed to establish its long-term safety and efficacy.

\section{Disclosure}

Fayyaz Ahmed has received honorarium to deliver training workshops for Allergan paid to British Association for the Study of Headache (BASH) and received honorarium to attend Allergan Advisory Board meetings. He is on the standing committee of the Headache Guidelines (CG150 Revision) for the National Institute of Clinical Excellence, trustee of the Migraine Trust, and educational officer for BASH. The authors report no other conflicts of interest in this work.

\section{References}

1. Headache Classification Committee of the International Headache Society (IHS). The international classification of headache disorders: 3rd edition (beta version). Cephalalgia. 2013;33(9):629-808.

2. Isler H. Episodic cluster headache from a textbook of 1745: Van Swieten's classic description. Cephalalgia. 1993;13:172-174.

3. Tonon C, Guttmann S, Volpini M, Naccarato S, Cortelli P, D'Alessandro R. Prevalence and incidence of cluster headache in the Republic of San Marino. Neurology. 2002;58:1407-1409.

4. Torelli P, Beghi E, Manzoni GC. Cluster headache prevalence in the Italian general population. Neurology. 2005;64:469-474.

5. Sjaastad O, Bakketeig LS. Cluster headache prevalence. Vaga study of headache epidemiology. Cephalalgia. 2003;23:528-533.

6. Rasmussen BK. Epidemiology of cluster headache. In: Olesen J, Goadsby PJ, editors. Cluster Headache and Related Conditions. Oxford: Oxford University Press; 1999:23-26.

7. Dodick DW, Rozen TD, Goadsby PJ, Silberstein SD. Cluster headache. Cephalalgia. 2000;14:787-803.

8. Mitsikostas DD, Edvinsson L, Jensen RH, et al. Refractory chronic cluster headache: a consensus statement on clinical definition from the European Headache Federation. J Headache Pain. 2014;15:79.

9. Edvisson L, Goadsby PJ. Neuropeptides in headache. Eur J Neurol. 1998;5:329-341.

10. Goadsby PJ, Edvinsson L. Human in vivo evidence for trigeminovascular activation in cluster headache. Neuropeptide changes and effects of acute attacks therapies. Brain. 1994;117(pt 3):427-434.

11. Fanciullacci M, Alessandri M, Sicuteri R, Marabini S. Responsiveness of the trigeminovascular system to nitroglycerine in cluster headache patients. Brain. 1997;120(pt 2):283-288.

12. Ekbom K, Greitz T. Carotid angiography in cluster headache. Acta Radiol. 1970;10:177-186.

13. Moskowitz MA. Cluster headache: evidence for a pathophysiologic focus in the superior pericarotid cavernous sinus plexus. Headache. 1988; 28:584-586.

14. Hardebo JE. How cluster headache is explained as an intracavernous inflammatory process lesioning sympathetic fibres. Headache. 1994; $34: 125-131$

15. Dodick DW, Capobianco DJ. Treatment and management of cluster headache. Curr Pain Headache Rep. 2001;5:83-91.

16. Kudrow L. Plasma testosterone levels in cluster headache: preliminary results. Headache. 1976;16:228-231.

17. Kudrow L. Plasma testosterone and LH levels in cluster headache. Headache. 1977;17:91-92.

18. Nelson RF. Testosterone levels in cluster and non-cluster migrainous patients. Headache. 1978;18:265-267.

19. Leone M, Partuno G, Vescovi A, Bussone G. Neuroendocrine dysfunction in cluster headache. Cephalalgia. 1990;10:235-239.

20. Waldenlind E, Ekbom K, Wetterberg L, et al. Lowered circannual urinary melatonin concentrations in episodic cluster headache. Cephalalgia. 1994;14:199-204.

21. Gillette MU, McArthur AJ. Circadian actions of melatonin at the suprachiasmatic nucleus. Behav Brain Res. 1996;73:135-139.

22. Hofman MA, Zhou IN, Swaab DF. Suprachiasmatic nucleus of the human brain: an immunocytochemical and morphometric analysis. J Comp Neurol. 1996;305:552-556.

23. Chazot G, Claustrat B, Brun J, Jordan D, Sassolas G, Schott B. A chronobiological study of melatonin, cortisol, growth hormone and prolactin secretion in cluster headache. Cephalalgia. 1984;4:213-220.

24. Waldenlind E, Gustafsson SA, Ekbom K, Wetterberg L. Circadian secretion of cortisol and melatonin in cluster headache during active cluster periods and remission. J Neurol Neurosurg Psychiatry. 1987;50:207-213.

25. May A, Bahra A, Büchel C, Frackowiak RS, Goadsby PJ. Hypothalamic activation in cluster headache attacks. Lancet. 1998;352:275-278.

26. Goadsby PJ. Cluster headache: new perspectives. Cephalalgia. 1999; 19(suppl 25):39-41.

27. Horton B. Histaminic cephalgia. Differential diagnosis and treatment: 1176 patients 1932-1955. Proc Staff Meet Mayo Clin. 1956; $31: 325-333$ 
28. Petersen AS, Barloese MC, Jensen RH. Oxygen treatment of cluster headache: a review. Cephalalgia. 2014;34(13):1079-1087.

29. Akerman S, Holland PR, Lasalandra MP, Goadsby PJ. Oxygen inhibits neuronal activation in the trigeminocervical complex after stimulation of trigeminal autonomic reflex, but not during direct dural activation of trigeminal afferents. Headache. 2009;49:1131-1143.

30. Kudrow L. Response of cluster headache attacks to oxygen inhalation. Headache. 1981;21:1-4.

31. Fogan L. Treatment of cluster headache. A double-blind comparison of oxygen v air inhalation. Arch Neurol. 1985;42:362-363.

32. Rozen TD. High oxygen flow rates for cluster headache. Neurology. 2004;63:593.

33. Cohen AS, Burns B, Goadsby PJ. High-flow oxygen for treatment of cluster headache: a randomized trial. JAMA. 2009;302:2451-2457.

34. Nilsson Remahl AI, Ansjön R, Lind F, Waldenlind E. Hyperbaric oxygen treatment of active cluster headache: a doubleblind placebocontrolled cross-over study. Cephalalgia. 2002;22:730-739.

35. Schnabel A, Bennet M, Schuster F, Roewer N, Kranke P. Hyper- or normobaric oxygen therapy to treat migraine and cluster headache pain. Cochrane review. Schmerz. 2008;22(129-132):134-136.

36. The Sumatriptan Cluster Headache Study Group. Treatment of acute cluster headache with sumatriptan. N Engl J Med. 1991;325:322-326.

37. Ekbom K, Monstad I, Prusinski A, Cole JA, Pilgrim AJ, Noronha D. Subcutaneous sumatriptan in the acute treatment of cluster headache: a dose comparison study. Acta Neurol Scand. 1993;88:63-69.

38. Ekbom K, Krabbe A, Micelli G, et al. Cluster headache attacks treated for up to three months with subcutaneous sumatriptan $(6 \mathrm{mg})$. Cephalalgia. 1995;15:230-236.

39. Göbel H, Lindner V, Heinze A, Ribbat M, Deuschl G. Acute therapy for cluster headache with sumatriptan: findings of a one year long-term study. Neurology. 1998;51:908-911.

40. Monstad I, Krabbe A, Micieli G, et al. Preemptive oral treatment with sumatriptan during a cluster period. Headache. 1995;35:607-613.

41. Van Vliet JA, Bahra A, Martin V, et al. Intranasal sumatriptan in cluster headache: randomized placebo-controlled double-blind study. Neurology. 2003;60:630-633.

42. Schuh-Hofer S, Reuter U, Kinze S, Einhaupl KM, Arnold G. Treatment of acute cluster headache with $20 \mathrm{mg}$ sumatriptan nasal spray - an open pilot study. J Neurol. 2002;249:94-99.

43. Hardebo JE, Dahlof C. Sumatriptan nasal spray ( $20 \mathrm{mg} / \mathrm{dose})$ in the acute treatment of cluster headache. Cephalalgia. 1998;18:487-489.

44. Bahra A, Gawel MJ, Hardebo JE, Millson D, Breen SA, Goadsby PJ. Oral zolmitriptan is effective in the acute treatment of cluster headache. Neurology. 2000;54:1832-1839.

45. Cittadini E, May A, Straube A, Evers S, Bussone G, Goadsby PJ. Effectiveness of intranasal zolmitriptan in acute cluster headache: a randomized, placebo-controlled, double-blind crossover study. Arch Neurol. 2006;63(11):1537-1542.

46. Hedlund C, Rapoport AM, Dodick DW, Goadsby PJ. Zolmitriptan nasal spray in the acute treatment of cluster headache: a meta-analysis of two studies. Headache. 2009;49(9):1315-1323.

47. Andersson PG, Jespersen LT. Dihydroergotamine nasal spray in the treatment of attacks of cluster headache. Cephalalgia. 1986;6:51-54.

48. Ekbom K. Treatment of cluster headache: clinical trials, design and results. Cephalalgia. 1995;15(suppl 15):33-36.

49. Kitrelle JP, Grouse DS, Seybold ME. Cluster headache: local anesthetic abortive agents. Arch Neurol. 1985;42:496-498.

50. Robbins L. Intranasal lidocaine for cluster headache. Headache. 1995; 35:83-84.

51. Costa A, Pucci E, Antonaci F, et al. The effect of intranasal cocaine and lidocaine on nitroglycerininduced attacks in cluster headache. Cephalalgia. 2000;20:85-91.

52. Couch JR, Ziegler DK. Prednisone therapy for cluster headache. Headache. 1978;18:219-221.

53. Prusinski A, Kozubski W, Szulc-Kuberska J. Steroid treatment in the interruption of clusters in cluster headache patients. Cephalalgia. 1987; 7(suppl 6):332-333.
54. Cianchetti C, Zudeas A, Marchei F. High-dose intravenous methylprednisolone in cluster headache. J Neurol Neurosug Psych. 1998; 64:418

55. Reija G, Nider G, Koscica N, et al. Dexamethasone in the treatment of episodic cluster headaches: an open study of 18 patients. Funct Neurol. 1998; 13:171-172.

56. Horton BT. Histaminic cephalgia. $J$ Lancet. 1952;72:92-98.

57. Neeb L, Anders L, Euskirchen P, Hoffmann J, Israel H, Reuter U. Corticosteroids alter CGRP and melatonin release in cluster headache episodes. Cephalalgia. 2015;35:317-326.

58. Antonaci F, Costa A, Candeloro E, Sjaastad O, Nappi G. Single highdose steroid treatment in episodic cluster headache. Cephalalgia. 2005; 25:290-295.

59. Kudrow L. Cluster Headache: Mechanisms and Management. Oxford; New York: Oxford University Press; 1980.

60. Holle D, Burmeister J, Scherag A, Ose C, Diener HC, Oberann M. Study protocol of Prednisone in episodic Cluster Headache (PredCH): a randomized, double-blind, placebo-controlled parallel group trial to evaluate the efficacy and safety of oral prednisone as an add-on therapy in the prophylactic treatment of episodic cluster headache with verapamil. BMC Neurol. 2013;13:99.

61. Tfelt-Hansen P, Bredberg U, Eyjolfsdottir GS, Paalzow L, TfeltHansen V. Kinetics of methysergide and its main metabolite, methylergometrine, in man. Cephalalgia. 1985;5(suppl 3):54-55.

62. Sicuteri F. Prophylactic and therapeutic properties of 1- methyl-lysergic acid butanolamide in migraine. Int Arch Allergy. 1959;15:300-307.

63. Olesen J, Tfelt-Hansen P, Welch K. The Headaches. 2nd ed. Philadelphia: Lippincott Williams and Wilkins; 1999:731-740.

64. May A. Cluster headache: pathogenesis, diagnosis, and management. Lancet. 2005;366:843-855.

65. Tflelt-Hansen P, Tfelt-Hansen J. Verapamil for cluster headache. Clinical pharmacology and possible mode of action. Headache. 2008; 49:117-125.

66. Gabai IJ, Spierings EHL. Prophylactic treatment of cluster headache with verapamil. Headache. 1989;29:167-168.

67. Leone M, D'Amico D, Frediani F, et al. Verapamil in the prophylaxis of episodic cluster headache: a double-blind study versus placebo. Neurology. 2000;54:1382-1385.

68. Francis GJ, Becker WJ, Pringshiem TM. Acute and preventive pharmacologic treatment of cluster headache. Neurology. 2010;75:463-473.

69. May A, Leone M, Afra J, et al; EFNS Task Force. EFNS guidelines on the treatment of cluster headache and other trigeminal-autonomic cephalalgias. Eur J Neurol. 2006;13:1066-1077.

70. Bussone G, Leone M, Peccarisi C, et al. Double blind comparison of lithium and verapamil in cluster headache prophylaxis. Headache. 1990; 30:411-417.

71. Goadsby PJ, Cohen AS, Matharu MS. Trigeminal autonomic cephalalgias; diagnosis and treatment. Curr Neurol Neurosci Rep. 2007;7:117-125.

72. Lanteri-Minet M, Silhol F, Piano V, Donnet A. Cardiac safety in cluster headache patients using the very high dose of verapamil ( $\geq 720 \mathrm{mg} /$ day). J Headache Pain. 2011;12(2):173-176.

73. Noll G, Luscher TF. Comparative pharmacological properties among calcium channel blockers: T-channel versus L-channel blockade. Cardiology. 1998;89(suppl 1):10-15.

74. Ekbom K. Lithium for cluster headache: review of the literature and preliminary results of long-term treatment. Headache. 1981;21:132-139.

75. Steiner TJ, Hering R, Couturier EG, Davies PT, Whitmarsh TE. Doubleblind placebo-controlled trial of lithium in episodic cluster headache. Cephalalgia. 1997;17:673-675.

76. Manzoni GC, Bono G, Lanfranchi M, Micieli G, Terzano MG, Nappi G. Lithium carbonate in cluster headache: assessment of its short and long-term therapeutic efficacy. Cephalalgia. 1983;3:109-114.

77. Shank RP, Gardocki JF, Streeter AJ, et al. An overview of the preclinical aspects of topiramate: pharmacology, pharmacokinetics, and mechanism of action. Epilepsia. 2000;41(suppl 1):S3-S9.

78. Storer RJ, Goadsby PJ. Topiramate inhibits trigemi-novascular neurons in the cat. Cephalalgia. 2004;24:1049-1056. 
79. Leone M, Dodick D, Rigamonti A, et al. Topiramate in cluster headache prophylaxis: an open trial. Cephalalgia. 2003;23:1001-1002.

80. Wheeler SD, Carrazana EJ. Topiramate-treated cluster headache. Neurology. 1999;53:234-236.

81. Láinez MJA, Pascual J, Pascual AM, Santonja JM, Ponz A, Salvador A. Topiramate in the prophylactic treatment of cluster headache. Headache. 2003;43:784-789.

82. Rozen TD. Cluster headache: diagnosis and treatment. Curr Pain Headache Rep. 2005;9(2):135-140.

83. Cutrer FM, Moskowitz MA. Wolff Award 1996. The actions of valproate and neurosteroids in a model of trigeminal pain. Headache. 1996;36(10):579-585.

84. Hering R, Kuritzky A. Sodium valproate in the treatment of cluster headache: an open trial. Cephalalgia. 1989;9:195-198.

85. Freitag FG, Diamond S, Diamond ML, et al. Divalproex sodium in the preventative treatment of cluster headache. Headache. 2000; 40:408.

86. Gallagher RM, Mueller LL, Freitag FG. Divalproex sodium in the treatment of migraine and cluster headaches. J Am Osteopath Assoc. 2002; 102(2):92-94.

87. El Amrani M, Massiou H, Bousser MG. A negative trial of sodium valproate in cluster headache: methodological issues. Cephalalgia. 2002; 22:205-208.

88. Wheeler S. Significance of migrainous features in cluster headache: divalproex responsiveness. Headache. 1998;38:547-551.

89. Ekbom K. Prophylactic treatment of cluster headache with a new serotonin antagonist, BC 105. Acta Neurol Scand. 1969;45:601-610.

90. Speight TM, Avery GS. Pizotifen (BC-105): a review of its pharmacological properties and its therapeutic efficacy in vascular headaches. Drugs. 1972;3:159-203.

91. Palermo A, Giglia G, Cosentino G, Raieli V, Brighina F, Fierro B. Two cases of cluster headache effectively treated with levetiracetam. Funct Neurol. 2013;28:63-64.

92. Miller S, Matharu M. Trigeminal autonomic cephalgias: beyond conventional treatments. Curr Pain Headache Rep. 2014;18(8):438.

93. Leandri M, Luzzani M, Cruccu G, Gottlieb A. Drug-resistant cluster headache responding to gabapentin: a pilot study. Cephalalgia. 2001; 21:744-746.

94. Schuh-Hofer S, Israel H, Neeb L, Reuter U, Arnold D. The use of gabapentin in chronic cluster headache patients refractory to firstline therapy. Eur J Neurol. 2007;14:694-696.

95. Hering-Hanit R, Gadoth N. The use of baclofen in cluster headache. Curr Pain Headache Rep. 2001;5:79-82.

96. Marks DR, Rapoport A, Padla D. A double-blind placebo-controlled trial of intranasal capsaicin for cluster headache. Cephalalgia. 1993; 13:114-116.

97. Leone M, D'Amico D, Moschiano F, Fraschini F, Bussone G. Melatonin versus placebo in the prophylaxis of cluster headache: a double-blind pilot study with parallel groups. Cephalalgia. 1996; 16:494-496.

98. Peres MF, Rozen TD. Melatonin in the preventive treatment of chronic cluster headache. Cephalalgia. 2001;21:993-995.

99. Kirkpatrick PJ, O'Brien MD, MacCabe JJ. Trigeminal nerve section for chronic migrainous neuralgia. Br J Neurosurg. 1993;7:483-490.

100. Hassenbusch SJ, Kunkel RS, Kosmorsky GS, Covington EC, Pillay PK. Trigeminal cisternal injection of glycerol for treatment of chronic intractable cluster headaches. Neurosurgery. 1991;29:504-508.

101. Pieper DR, Dickerson J, Hassenbusch SJ. Percutaneous retrogasserian glycerol rhizolysis for treatment of chronic intractable cluster headaches: long-term results. Neurosurgery. 2000;46:363-370.

102. Donnet A, Tamura M, Valade D, Regis J. Trigeminal nerve radiosurgical treatment in intractable chronic cluster headache: unexpected high toxicity. Neurosurgery. 2006;59:1252-1257.
103. McClelland S 3rd, Barnett GH, Neyman G, Suh JH. Repeat trigeminal nerve radiosurgery for refractory cluster headache fails to provide long-term pain relief. Headache. 2007;47:298-300.

104. Matharu MS, Goadsby PJ. Persistence of attacks of cluster headache after trigeminal nerve root section. Brain. 2002;125:976-984.

105. Lovely TJ, Kotsiakis X, Jannetta PJ. The surgical management of chronic cluster headache. Headache. 1998;38(8):590-594.

106. Leone M, Franzini A, Bussone G. Stereotactic stimulation of posterior hypothalamic gray matter for intractable cluster headache. N Engl J Med. 2001;345:1428-1429.

107. Leone M, Franzini A, Broggi G, May A, Bussone G. Long-term follow up of bilateral hypothalamic stimulation for intractable cluster headache. Brain. 2004;127:2259-2264.

108. Schoenen J, Di Clemente L, Vandenheede M, et al. Hypothalamic stimulation in chronic cluster headache: a pilot study of efficacy and mode of action. Brain. 2005;128(pt 4):940-947.

109. Franzini A, Ferroli P, Leone M, Broggi G. Stimulation of the posterior hypothalamus for treatment of chronic intractable cluster headaches: first reported series. Neurosurgery. 2003;52:1095-1101.

110. Magis D, Schoenen J. Advances and challenges in neurostimulation for headaches. Lancet Neurol. 2012;11:708-719.

111. Leone M, May A, Franzini A, et al. Deep brain stimulation for intractable chronic cluster headache: proposals for patient selection. Cephalalgia. 2004;24:934-937.

112. Burns B, Watkins L, Goadsby PJ. Treatment of intractable chronic cluster headache by occipital nerve stimulation in 14 patients. Neurology. 2009; 72:341-345.

113. Lainez MJA, Piera A, Salvador A, et al. Efficacy and safety of occipital nerve stimulation for treatment of chronic cluster headache. Headache. 2008;48(suppl 1):S15.

114. Schwedt TJ, Dodick DW, Hentz J, Trentman TL, Zimmerman RS Occipital nerve stimulation for chronic headache - long-term safety and efficacy. Cephalalgia. 2007;27:153-157.

115. Lambru G, Abu Bakar N, Stahlhut L, et al. Greater occipital nerve blocks in chronic cluster headache: a prospective open-label study. Eur J Neurol. 2014;21:338-343.

116. Leroux E, Valade D, Taifas I, et al. Suboccipital steroid injections for transitional treatment of patients with more than two cluster headache attacks per day: a randomised, double-blind, placebo-controlled trial. Lancet Neurol. 2011;10:891-897.

117. Ambrosini A, Vandenheede M, Rossi P, et al. Suboccipital injection with a mixture of rapid- and long-acting steroids in cluster headache: a double-blind placebo-controlled study. Pain. 2005;118:92-96.

118. Gooriah R, Ahmed F. Therapeutic uses of botulinum toxin. J Clin Toxicol. 2015;5:225.

119. Gooriah R, Ahmed F. OnabotulinumtoxinA for chronic migraine: a critical appraisal. Ther Clin Risk Manag. 2015;11:1003-1013.

120. Cernuda-Morollon E, Ramon C, Martinez-Camblor P, SerranoPertierra E, Larrosa D, Pascual J. OnabotulinumtoxinA decreases interictal CGRP plasma levels in chronic migraine patients. Pain. 2015; 156(5):820-824.

121. Sostak P, Krause P, Forderreuther S, Reinisch V, Straube A. Botulinum toxin type-A therapy in cluster headache: an open study. $J$ Headache Pain. 2007;8:236-241.

122. Robbins L. Botulinum toxin A (Botox) for cluster headache: 6 cases. Cephalalgia. 2001;21:492-503.

123. Freund BJ, Schwartz M. The use of Botulinum toxin-A in the treatment of refractory cluster headache: case reports. Cephalalgia. 2000; 20:235-233. 
Therapeutics and Clinical Risk Management

Dovepress

\section{Publish your work in this journal}

Therapeutics and Clinical Risk Management is an international, peerreviewed journal of clinical therapeutics and risk management, focusing on concise rapid reporting of clinical studies in all therapeutic areas, outcomes, safety, and programs for the effective, safe, and sustained use of medicines. This journal is indexed on PubMed Central, CAS,

EMBase, Scopus and the Elsevier Bibliographic databases. The manuscript management system is completely online and includes a very quick and fair peer-review system, which is all easy to use. Visit $\mathrm{http}: / / \mathrm{www}$.dovepress.com/testimonials.php to read real quotes from published authors.

Submit your manuscript here: http://www.dovepress.com/therapeutics-and-clinical-risk-management-journal 